\title{
Upaya Dinas Pariwisata Ternate Dalam Mengatasi Penurunan Kunjungan Wisatawan Di Daya Tarik Wisata Pantai Sulamadaha
}

Ayu Astrid Fabanyo ${ }^{\mathrm{a}, 1}$, I Gede Anom Sastrawana,2

1ayuastridfabanyo@gmail.com, 2anom_sastrawan@unud.ac.id

aProgram Studi Sarjana Destinasi Pariwisata, Fakultas Pariwisata, Universitas Udayana JL. Dr. R,Goris, Denpasar,Bali 80232 Indonesia.

\begin{abstract}
This study aims to determine the factors that cause a decrease in tourist visits and efforts made by the Ternate City Tourism Office in overcoming the decreasing intensity of tourist visits in Sulamadaha Beach Tourism Attractions. Ternate located in North Maluku Province. Ternate is one of 10 districts in North Maluku Province that have many tourist attractions, for example Sulamadaha Beach. Sulamadaha Beach is an attraction that is managed directly by the Ternate City Tourism Office and the local community, Sulamadaha Beach has beautiful underwater natural beauty, according to data from the Ternate City Tourism Office Sulamadaha Beach is the most popular destination for tourists, but this does not last long as it is known from the data of tourist visits that Sulamadaha Beach every year has decreased, related to this, it will be research about "The efforts of the City of Ternate Tourism Office in Overcoming the Decreasing Intensity of Tourist Visits in Sulamadaha Beach Attractions"

The research method used in this study is the type of research is descriptive research with a qualitative approach. The results of this study indicate that there are several factors that cause a decrease in the intensity of tourist visits in Sulamadaha Beach Tourism by using the concept of Sapta Charms, namely safe factors, orderly factors, and friendly factors, Ternate City Tourism Office has also designed several programs to stabilize the problem. One of the efforts made by the agency is to add supporting facilities to tourist attractions.
\end{abstract}

Keywords :efforts, decline

\section{PENDAHULUAN}

Kota Ternate menjadi salah satu kota di Provinsi Maluku Utara yang mempunyai berbagai macam daya tarik wisata. daya tarik wisata di Kota Ternate sendiri menyajikan wisata seperti wisata bersejarah, wisata ekowisata, wisata bahari yaitu berupa wisata alamnya dan wisata laut. Wisata sejarah sepertii Kedaton Kesultanan Ternate, Peninggalan beberapa benteng oleh bangsa kolonial Spanyol, Belanda dan Portugis. Untuk wisata alam di Kota Ternate ada dua yaitu Danau Tolire Besar serta Danau Tolire Kecil. Sedangkan untuk wisata laut ada Pantai Jikomalamo, Pantai Kastela dan Pantai Sulamadaha.

Pantai Sulamadaha adalah sebuah pantai pasir hitam yang terletak $\pm 14 \mathrm{Km}$ dari Pusat Kota Ternate (Dinas Pariwisata Kota Ternate, 2019). Pantai Sulamadaha termasuk salah satu pantai terbaik di Kota Ternate yang mempunyai daya tarik tersendiri yaitu air jernihnya yang menyerupai kaca serta keindahan suasana alam yang menjadikan Pantai Sulamadaha banyak didatangi oleh wisatawan baik lokal dan mancanegara, tak heran jika pantai ini merupakan destinasi unggulan bagi masyarakat Kota Ternate. Pantai Sulamadaha dikelola langsung oleh Dinas Pariwisata Kota Ternate serta masyarakat setempat sehingga membuat pantai ini cukup terawat. Fasilitas-fasilitas yang tersedia mulai dari lahan parkir, kantin-kantin makanan, toilet umum, gazebo, tempat sampah, serta fasilitas pendukung lainnya disediakan oleh Dinas Pariwisata Kota Ternate, dinas pariwisata juga memberdayakan masyarakat setempat. Seperti mendirikan kantinkantin yang nantinya dapat dijadikan sumber mata pencaharian bagi masyarakat setempat tanpa dimintai biaya sewa atau gratis, hal ini membuat masyarakat setempat sangat menjaga serta merawat Pantai Sulamadaha dengan baik agar wisatawan yang berkunjung bisa menikmati pantai ini.

Pada 5 tahun terakhir pantai sulamadaha selalu ramai pengunjung. Akan tetapi berdasarkan data dari Dinas Pariwisata Kota Ternate mengenai data kunjungan wisatawan di Pantai Sulamadaha telah terjadi penurunan tingkat kunjungan wisatawan dari tiga tahun terakhir, hal ini telah dibuktikan dari data kunjungan sejak tahun 2015 yaitu kunjungan wisatawan mencapai 78,450 kunjungan, sedangkan pada awal tahun 2018 jumlah wisatawan yang mengunjungi Pantai Sulamadaha terlihat menurun drastis karena hanya mencapai 27,196 angka kunjungan.

Tak hanya itu, para pelaku usaha wisata seperti pemilik kantin di Pantai Sulamadaha pun turut 
merasakan dampak dari penurunan ini, informasi tersebut diketahui langsung saat penulis mewawancarai salah satu pemilik kantin di Pantai Sulamadaha yang mengatakan bahwa pada saat ini Pantai Sulamadaha sangat sepi pengunjung yang mengakibatkan terjadinya krisis ekonomi. Karena bagi mereka Pantai Sulamadaha merupakan sumber pendapatan utama bagi masyarakat lokal maka dari itu penting bagi penulis untuk meneliti tentang "Upaya Dinas Pariwisata Kota Ternate Dalam Mengatasi Penurunan Jumlah Kunjungan Wisatawan Di Daya Tarik Wisata Pantai Sulamadaha" agar dapat memahami dengan jelas penyebab terjadinya penurunan jumlah kunjungan wisatawan serta agar dapat mengetahui tentang upaya-upaya yang dilakukan oleh Dinas Pariwisata Kota Ternate guna menstabilkan kembali tingkat kunjungan wisatawan di Pantai Sulamadaha.

Pada penelitian ini penyebab terjadinya penurunan kunjungan jumlah wisatawan diteliti menggunakan konsep sapta pesona menurut Arony (2012:05) yaitu Sapta Pesona dapat dimengerti sebagai 7 (tujuh) unsur yang terkandung pada setiap produk pariwisata serta dipergunakan sebagai tolak ukur peningkatan nilai pada kualitas produk pariwisata. Sapta pesona adalah jabaran konsep Sadar Wisata yang terkait dengan dukungan dan peran dari masyarakat yang dijadikan sebagai tuan rumah dalam upaya agar dapat menciptakan lingkungan serta suasana kondusif yang mampu untuk mendorong perkembangan industri pariwisata melalui pembentukan tujuh unsur dalam Sapta Pesona tersebut. Selain itu Sapta Pesona juga dapat dikatakan sebagai kebijakan dalam dunia pariwisata tanah air. Melalui Sapta Pesona, diharapkan dapat terwujudnya suasana kebersamaan antara semua pihak untuk terciptanya lingkungan alam dan budaya luhur bangsa, dan untuk membahas mengenai upaya pemerintah dalam menangani penurunan tingkat kunjungan wisatawan dalam penelitian ini menggunakan konsep upaya. Menurut Poerdaminta 2002 upaya upaya merupakan sebuah usaha untuk menyampaikan maksud, akal dan ikhtisar. Upaya merupakan segala sesuatu yang bersifat mengusahakan pada sesuatu hal agar dapat lebih berdaya guna dan berhasil guna sesuai dengan maksud, tujuan dan fungsi serta manfaat mengapa hal tersebut dilaksanakan. Serta menggunakan beberapa konsep lainnya seperti konsep stakeholder pariwisata, menurut Hetifah (2003:3) Pengertian stakeholder menurut Hetifah (2003:3) dapat dimaknai sebagai individu, kelompok atau organisasi yang mempunyai suatu kepentingan tertentu, terlibat, atau dipengaruhi (secara positif maupun negatif) oleh kegiatan atau sebuah program pembangunan. Pembangunan kepariwisataan diketahui melibatkan tiga stakeholder yang saling terkait yaitu pemerintah, swasta, dan masyarakat (Rahim,2012:1)

Penelitian sebelumnya, yaitu berupa jurnal penelitian yang berjudul "Upaya Dinas Pariwisata dan Kebudayaan Kota Batam Dalam Kegiatan Wisata Belanja di Kepulauan Riau (Suatu Studi Kualitatif)" pada tahun 2013 yang dilakukan oleh Raja Riza Amanda Putri, IGA Oka Mahagangga mahasiswa Universitas Udayana. Penelitian ini bertujuan untuk mengetahui bagaimana bentuk upaya Dinas Pariwisata dan Kebudayaan untuk mempromosikan kegiatan wisata belanja dan ingin mengetahui fungsi kegiatan dari promosi wisata belanja yang dilakukan oleh Dinas Pariwisata dan Kebudayaan dilihat dari pengamatan langsung dan wawancara. Penelitian ini menggunakan penelitian kualitatif dan juga kuantitatif. Sumber data yang dipergunakan dalam penelitian ini berasal dari data primer dan data sekunder. Metode pengumpulan data yang dipakai dalam penelitian ini merupakan metode wawancara mendala. Berdasarkan hasil penelitian yang didapatkan dari penelitian ini menunjukan bahwa kegiatan promosi wisata belanja oleh Dinas Pariwisata dan Kebudayaan Kota Batam sudah terlaksanakan namun belum optimal. Hal ini disebabkan oleh pelaksanaan kegiatan promosi tersebut menemui beberapa kendala dilapangan yang harus perhatikan bagi semua pemangku kepentingan dan harus segera diperbaiki, macam-macam dari upaya Dinas Pariwisata dan Kebudayaan Kota Batam adalah untuk mempromosikan wisata belanja seperti kegiatan penjualan pribadi, promosi penjualan, periklanan, hubungan masyarakat dan pemasaran langsung.

Relevansi antara penelitian sebelumnya dengan penelitian yang sedang dilakukan adalah, kedua penelitian tersebut memiliki fokus yang sama yaitu keduanya sama-sama membahas tentang upayaupaya yang dilakukan Dinas Pariwisata dalam pengembangan sebuah daya tarik wisata, sedangkan perbedaan yang terdapat antara penelitian sebelumnya dengan penelitian yang sedang dilakukan terletak pada lokasi penelitian, penelitian sebelumnya berlokasi di Dinas Pariwisata dan Kebudayaan Kota Batam dan penelitian yang sedang dilakukan berlokasi di Pantai Sulamadaha Kota Ternate, perbedaan berikutya terletak pada tahun penelitian, penelitian yang dilakukan sebelumnya pada tahun 2013 dan penelitian yang sedang dilakukan pada tahun 2019.

Penelitian sebelumnya yang kedua yaitu berupa jurnal yang berjudul "Optimalisasi Pengelolaan Pantai Sulamadaha Dalam Meningkatkan Retribusi Daerah Di Sektor Kepariwisataan Di Kota Ternate Provinsi Maluku 
Utara" pada tahun 2018 yang dilakukan oleh Edward Alendra mahasiswa Institut Pemerintahan Dalam Negeri (IPDN), penelitian ini bertujuan untuk mengetahui upaya Dinas Pariwisata dalam melaksanakan fungsinya dan mengetahui faktor pendukung serta faktor penghambat dalam pengelolaan Pantai Sulamadaha dan meningkatkan Retribusi Daerah di Sektor Kepariwisataan di Kota Ternate, Metode yang digunakan dalam penelitian ini adalah metode penelitian diskriptif dengan pendekatan induktif. Teknik pengumpulan data meliputi dokumentasi, wawancara. Hasil penelitian ini menunjukan bahwa kinerja Dinas Pariwisata Kota Ternate sudah terarah kepada retribusi daerah Kota Ternate, dan juga Pantai Sulamadaha berpotensi untuk dikembangkan. Upaya yang dilakukan oleh Dinas Pariwisata adalah dengan mengembangkan obyek wisata yang ada, pembangunan sarana, memperbaiki dan merawat sarana dan meningkatkan pengawasan di Pantai Sulamadaha.

Relevansi penelitian sebelumnya dan penelitian yang sedang dilakukan yaitu, penelitian tersebut memiliki fokus yang terbilang sama yaitu samasama membahas mengenai upaya yang dilakukan Dinas Pariwisata Kota Ternate dalam mengembangkan daya tarik wisata Pantai Sulamadaha, persamaan berikutnya terletak pada lokasi penelitian yang sama-sama berlokasi di Pantai Sulamadaha, sedangkan perbedaannya dengan penelitian yang sedang dilakukan terletak pada judul penelitian dan tahun dari kedua penelitian tersebut, penelitian pertama dilakukan pada tahun 2018 sedangkan penelitian yang sedang dilakukan pada tahun 2019.

\section{METODE PENELITIAN}

Penelitian ini berlokasi di Pantai Sulamadaha, Desa Sulamadaha diketahui terletak di Kota Ternate, Provinsi Maluku Utara. Lokasi ini berjarak sekitar $\pm 14 \mathrm{Km}$ dari Pusat Kota Ternate dan dapat ditempuh menggunakan kendaraan pribadi. Pantai Sulamadaha buka setiap hari mulai pukul 08.00 WIT sampai dengan pukul 17.00 WIT dan memiliki tiket masuk dengan harga Rp 8000,- akses menuju Pantai Sulamadaha dapat ditempuh menggunakan kendaraan pribadi atau dengan rental mobil dan motor.

Dalam upaya mempertegas batasan lingkup permasalahan pada penelitian ini, maka dapat dijabarkan ruang lingkup penelitian yakni: (1) Deskripsi mengenai faktor penyebab penurunan tingkat kunjungan wisatawan di Pantai Sulamadaha, arah data meliputi: keamanan, ketertiban, kebersihan, keramah-tamahan. (2)Pemahaman mengenai upaya dinas pariwisata Kota Ternate dalam mengatasi penurunan tingkat kunjungan wisatawan di daya tarik wisata Pantai Sulamadaha adalah mengenai program-program yang akan dilakukan oleh Dinas Pariwisata Kota Ternate dalam mengatasi penurunan jumlah kunjungan wisatawan di daya tarik wisata Pantai Sulamadaha.

Jenis data yang dipergunakan dalam penelitian ini adalah data kualitatif dengan melampirkan data mengenai gambaran umum objek penelitian yang berupa gambaran umum Desa Sulamadaha serta gambaran umum tentang Daya Tarik Wisata Pantai Sulamadaha dan upaya Dinas Pariwisata Kota Ternate dalam mengatasi penurunan jumlah kunjungan wisatawan.

Sumber data yang dipergunakan dalam penelitian ini adalah data primer dan data sekunder, berupa atraksi wisata Pantai Sulamadaha, harga tiket, penyebab terjadinya penurunan kunjungan wisatawan, dan upaya yang dilakukan oleh Dinas Pariwisata Kota Ternate. Sedangkan data sekunder yang dipergunakan dalam penelitian ini adalah berupa jumlah kunjungan wisatawan, dan penelitian sebelumnya.

Teknik pengumpulan data dalam penelitian ini meliputi observasi, wawancara (Suryawan dkk., 2017) dan studi kepustakaan (Moleong, 2002). Teknik analisis data yang dipergunakan dalam penelitian ini adalah deskriptif kualitatif. (Bungin, 2007).

\section{HASIL DAN PEMBAHASAN \\ 2.1 Gambaran Umum}

Pantai Sulamadaha merupakan sebuah pantai berpasir hitam yang berlokasi di Kelurahan Sulamadaha Kota Ternate Provinsi Maluku Utara. Pantai Sulamadaha berjarak $15 \mathrm{~km}$ dari pusat Kota Ternate. Pantai Sulamadaha mempunyai pesona tersendiri yaitu memiliki air jernih yang menyerupai kaca yang belum tercemar serta memiliki terumbu karang yang diantaranya merupakan spesies langka, selain itu keindahan bawa laut di Pantai Sulamadaha juga sangat berpotensi sehingga sering dijadikan tempat untuk diving dan snorkling oleh wisatawan yang berkunjung, suasana yang asri di Pantai Sulamadaha juga membuat wisatawan yang datang merasa nyaman karena selain memiliki keindahan laut, Pantai Sulamadaha juga berpapasan langsung dengan Pulau Hiri yang membuat pemandangan di Pantai Sulamadaha tampak indah.

Tingkat Kunjungan Wisatawan Di Daya Tarik Wisata Pantai Sulamadaha bisa dibilang mengalami penurunan, menurut data kunjungan dari Dinas Pariwisata Kota Ternate Pantai Sulamadaha pada tahun 2018 mengalami penurunan drastis jika dilihat dari tingkat kunjungan wisatawan per tahunnya. Pada tahun 2015 kunjungan wisata di Pantai Sulamadaha terlihat sangat tinggi yaitu 
mencapai 78,450 kunjungan. Penyebab penurunan kunjungan wisatawan di Pantai Sulamadaha dipengaruhi oleh beberapa faktor yang salah satunya adalah adanya destinasi wisata baru yang menghadirkan atraksi baru yang membuat wisatawan beralih ke destinasi tersebut.

Berikut merupakan data kunjungan wisatawan yang berkunjung ke Pantai Sulamadaha empat tahun terakhir.

Tabel 2.1

Data Kunjungan Wisatawan Nusantara dan Mancanegara ke Daya Tarik Wisata Pantai Sulamadaha Empat Tahun Terakhir

\begin{tabular}{|l|l|l|l|l|l|}
\hline $\begin{array}{l}\text { N } \\
\text { o }\end{array}$ & DTW & $\begin{array}{l}\text { Tahu } \\
\text { n } \\
2015\end{array}$ & $\begin{array}{l}\text { Tahu } \\
\text { n } \\
2016\end{array}$ & $\begin{array}{l}\text { Tahu } \\
\text { 2017 } \\
2017\end{array}$ & $\begin{array}{l}\text { Tah } \\
\text { un } \\
201 \\
8\end{array}$ \\
\hline 1 & $\begin{array}{l}\text { Pantai } \\
\text { Sulamadah } \\
\text { a }\end{array}$ & $\begin{array}{l}78,45 \\
0\end{array}$ & $\begin{array}{l}42,35 \\
0\end{array}$ & $\begin{array}{l}38,20 \\
8\end{array}$ & $\begin{array}{l}27,1 \\
96\end{array}$ \\
\hline & Jumlah & \multicolumn{3}{|c|}{186,204} \\
\hline
\end{tabular}

Sumber: Dinas Pariwisata Kota Ternate

Berdasarkan data tabel 2.1 di atas di atas dapat diketahui bahwa sebelum terjadinya penurunan drastis pada tahun 2018, jumlah kunjungan wisatawan pada tahun 2015 terlihat meningkat yaitu mencapai 78,450 kunjungan, kemudian menurun pada tahun 2016 yaitu hanya sebanyak 42,350 kunjungan, kemudian di tahun berikutnya angka kunjungan wisatawan terus mengalami penurunan yaitu hingga pada tahun 2018 yang hanya mencapai 27,196 kunjungan wisatawan. Data menunjuk bahwa pada tahun 2015 merupakan kunjungan wisatawan tertinggi ke Pantai Sulamadaha yaitu sebanyak 78,450 wisatawan.

Komponen 4A di Daya Tarik Wisata Pamtai Sulamadaha adalah (a) Atraksi (attractions) Pantai Sulamadaha memiliki keindahan pantai yang telah menjadi daya tarik utama bagi wisatawan yang ingin berkunjung, hamparan pasir hitam yang dimiliki Pantai Sulamadaha serta teluk yang memiliki air yang sebening kaca membuat Pantai Sulamadaha terlihat sangat indah, kalau di Kalimantan Timur terkenal dengan Danau Labuan Cermin maka di Ternate mempunyai Pantai Sulamadaha, tak hanya itu keindahan dasar lautnya juga cukup indah dimana terdapat beranekaragam ikan-ikan kecil dan juga terdapat begitu banyak jenis coral dan juga terumbu karang yang menghiasi dasar pantai, wisatawan yang datang selain menikmati suasana alam Pantai Sulamadaha juga dapat menikmati laut Sulamadaha seperti berenang, bermain olahraga air seperti diving, dan snorkling. (b) Aksesbilitas (accesibilities) Perjalanan menuju Pantai Sulamadaha dapat ditempuh sekitar 30 menit dari pusat Kota. Akses jalan menuju Pantai Sulamadaha pun terbilang cukup baik dengan jalan yang telah di aspal dan tidak berlubang, pada saat tiba di Pantai Sulamadaha wisatawan dapat melakukan tracking sekitar 10 menit dari gerbang pintu masuk Pantai Sulamadaha untuk menuju teluk Saomadaha, ada beberapa anak tangga yang harus dilewati wisatawan agar tiba di Teluk Saomadaha. (c) Amenitas atau fasilitas (amenities) daya tarik wisata Pantai Sulamadaha, menyediakan beberapa fasilitas untuk menunjang pengembangan daya tarik wisata Pantai Sulamadaha. fasilitas itu meliputi fasilitas pariwisata dan fasilitas pendukung. Fasilitas pariwisata yang terdapat di daya tarik wisata Pantai Sulamadaha berupa Pantai Sulamadaha itu sendiri dan tracking yang ada. tracking merupakan daya tarik tersendiri bagi wisatawan yang ingin mengambil aktivitas tambahan, kegiatan ini menjadi salah satu aktivitas yang sering dilakukan wisatawan saat berwisata, hal ini sebagai salah satu bentuk pengembangan pariwisata yang berperspektif alam. Fasilitas dasar yang terdapat di daya tarik wisata Pantai Sulamadaha ialah tersedianya kantin-kantin yang menjual aneka macam makanan dan minuman, seperti mie goreng, minuman soda, es kelapa muda dan snack-snack. Selain itu disediakannya tempat parkir, toilet, masjid,dan gazebo. Di Pantai Sulamadaha memiliki 7 (tujuh) kantin makanan yang disediakan oleh Dinas Pariwisata Kota Ternate, 4 (empat) toilet, 2 (dua) lahan parkir, 1 (satu) masjid dan 6 (enam) gazebo yang disediakan oleh pemerintah. (d) Ancillary service Ancillary merupakan faktor penting yang mempengaruhi pengembangan suatu daya tarik wisata karena tanpa ancillary maka tidak ada tujuan pengelolaan yang jelas sehingga eksistensi dari ancillary diperlukan untuk menentukan arah kedepannya dari daya tarik tersebut. sistem yang mengelola daya tarik wisata Pantai Sulamadaha yakni dikelola langsung oleh Dinas Pariwisata dan didukung oleh kelompok sadar wisata dimana pokdarwis merupakan organisasi kelompok yang dibentuk atas kesadaran masyarakat lokal sebagai parsitipator dalam rangka melestarikan sapta pesona yang ada di daya tarik wisata Pantai Sulamadaha. Dalam pengelolaan Daya Tarik Wisata Pantai Sulamadaha, pembagian hasil retribusi penjualan tiket, sepenuhnya masuk ke PAD, selain itu masyarakat yang berjualan di kawasan pantai sulamadaha hasilnya adalah milik masyarakat. (1)Peran Stakeholder, Pemerintah Di Pantai Sulamadaha pemerintah mempunyai peranan yang besar dalam pengelolaan di daya tarik wisata pantai sulamadaha, Dinas Pariwisata Kota Ternate merupakan pihak utama yang mengelola pantai sulamadaha dari segi retribusi tiket, pembangunan infrastruktur, dan fasilitas-fasilitas pendukung lainnya(2)Swasta di pantai sulamadaha belum ada kerja sama antara pihak swasta dalam 
pengembangan daya tarik wisata di pantai sulamadaha seperti hotel, restoran dan fasilitas penunjang lainnya. (3) Masyarakat, Sebagai pengelola daya tarik wisata pantai sulamadaha, masyarakat desa sulamadaha memiliki peran sebagai pihak yang turut membantu jalannya pantai sulamadaha, seperti menjaga pantai sulamadaha dengan menyediakan beberapa tempat usaha yang difasilitasi oleh Dinas Pariwisata Kota Ternate agar dapat menjaga pantai sulamadaha dengan baik.

Dinas Pariwisata Kota Ternate tampak harus memperhatikan fokus sasaran dalam rencana kerja masing-masing bidang mulai dari SDM, produk dan pasar potensial wisatawan. Hal ini dapat diupayakan dengan koordinasi terstruktur di dalam OPD Dinas Pariwsiata Kota Ternate. Kendala koordinasi antar bidang di dalam lembaga seperti dinas pariwisata memang masih menjadi permasalahan pembangunan pariwisata di Indonesia (Roku, dkk., 2016).

Selama tiga tahun terakhir jumlah kunjungan wisatawan di daya tarik Pantai Sulamadaha mengalami perubahan pada angka kunjungan yakni penurunan yang terus terjadi di setiap tahun dapat diilihat pada Kunjungan tertinggi menurut data dari Dinas Pariwisata Kota Ternate pada tahun 2015 yakni mencapai sebanyak 78,450 wisatawan, namun pada tahun-tahun berikutnya jumlah kunjungan mengalami penurunan yaitu pada tahun 2016, tahun 2017, dan tahun 2018.

\subsection{Faktor Penyebab Terjadinya Penurunan Kunjungan Wisatawan}

Beberapa faktor pemicu terjadinya penurunan jumlah kunjungan wisatawan yaitu, faktor keamanan, faktor kebersihan, faktor ketertiban dan faktor keramah-tamahan, berikut merupakan definisi mengenai beberapa faktor penyebab penurunan kunjungan wisatawan di Daya Tarik Pantai Sulamadaha;

(a)Keamanan, Pantai Sulamadaha belum dapat dikatakan sebagai pantai yang aman, hal ini dikarenakan pantai ini belum memiliki petugas keamanan yang menjaga keamanan di area wisata Pantai Sulamadaha, yang menjadikan banyak oknum yang melakukan pemancingan ikan yang dilarang karena menggunakan bom yang dapat menghancurkan ikan-ikan di laut Pantai Sulamadaha, jika hal ini dibiarkan terus menerus maka ikan-ikan yang ada di laut Pantai Sulamadaha akan mati dan hal ini akan merusak citra Pantai Sulamadaha karena Pantai Sulamadaha sendiri terkenal akan keindahan alam bawah lautnya. (b) Ketertiban, Di Pantai Sulamadaha sendiri dapat dikatakan telah cukup tertata hal ini terlihat dari kantin-kantin yang baru di renovasi oleh pemerintah daerah yang memperlihatkan kesan rapi, juga toilet yang juga baru di renovasi, gazebo-gazebo yang telah di tata dengan baik, , namun dalam hal lain penempatan tempat duduk yang disedakan oleh para pelaku usaha terlihat tidak terlalu rapi dan sangat dekat dengan tepi pantai membuat penampakan yang terkesan tidak indah dan cukup berbahaya jika air laut mengalami pasang, selain itu fasilitas seperti tempat duduk yang disediakan oleh para pelaku usaha di Pantai Sulamadaha pun terbilang sudah tidak baik hal ini dapat dilihat dari kondisi tempat-tempat duduk yang terlihat tidak layak. (c) Kebersihan, Kebersihan Pantai Sulamadaha, hal ini meliputi kondisi lingkungan areal Pantai Sulamadaha, yang masih sangat tidak terjaga karena ditemukannya banyak sampah yang tersebar di permukaan laut, wisatawan masih kurang mengerti betapa pentingnya kebersihan jadi sudah tidak heran jika mereka membuang sampah sembarangan yang mengakibatkan lingkungan kurang bersih, sampah di pantai sulamadaha juga berupa daun-daun yang jatuh di sekitar pantai sulamadaha yang mengotori jalanan serta area pantai. (d) Keramah-tamahan, Keramah-tamahan di Pantai Sulamadaha terbilang belum cukup baik yang dapat dibuktikan dengan sebuah hasil wawancara kepada salah satu wisatawan yang berkunjung.

\subsection{Upaya Dinas Pariwisata Kota Ternate Dalam Mengatasi Penurunan Jumlah Intensitas Kunjungan Wisatawan}

Upaya Yang Di Lakukan Dinas Pariwisata Kota Ternate Dalam Mengatasi Penurunan Tingkat Kunjungan Wisatawan antara lain yaitu ;

(a)Program Dinas Pariwisata Kota Ternate Di Pantai Sulamadaha, Dinas Pariwisata menjadi salah satu yang mempunyai peran penting dalam mengatasi permasalahan yang terjadi di Daya Tarik Pantai Sulamadaha, yaitu dengan cara membuat beberapa strategi untuk mengembalikan tingkat kunjungan wisatawan di Pantai Sulamadaha. menurut hasil wawancara bersama Kepala Dinas Pariwisata Kota Ternate, Dinas Pariwisata Kota Ternate akan melakukan beberapa program pada tahun 2019 guna menstabilkan tingkat kunjungan wisatawan yang saat ini berada pada fase rejuvenation atau peremajaan, berikut merupakan beberapa program rancangan jangka pendek yang akan dilakukan di pantai sulamadaha; (1)Peningkatan fasilitas, yang dimaksud peningkatan fasilitas yaitu memperbaharui fasilitas-fasilitas yang telah rusak, seperti memperbaiki toilet agar lebih baik lagi, banyak gazebo yang terlihat sudah tidak memadai termasuk akomodasi-akomodasi yang sudah tidak layak pakai. Seperti yang diketahui ada beberapa fasilitas pendukung di pantai sulamdaha yang terbilang sudah tidak layak pakai. (2) Penambahan atraksi buatan, berdasarkan hasil wawancara 
dengan Kepala Dinas Pariwisata Kota Ternate dikatakan pada tahun ini atau pada tahun 2019, Dinas Pariwisata Kota Ternate akan menambah wahana-wahana baru yaitu seperti flying fox, wahana anak-anak, dan atraksi penunjang lainnya guna menarik minat wisatawan untuk berkunjung. (3) Memajukan SDM baik perangkat pariwisata serta Stakeholder. Sumber daya manusia yang membantu jalannya pengembangan pembangunan kepariwisataan tentunya sudah harus mengerti visi dan misi pembanguan kepariwisataan sehingga dengan kesadaran sendiri mempuyai keinginan untuk melakukan berdasarkan kemampuannya berperan serta dalam pengembangan yang ada di kepariwisataan daerah. Kapasitas SDM pariwisata baik perangkat pemerintah atupun swasta serta masyarakat harus ditingkatkan. Sumber daya manusia yang telah menjadi penggerak, perencana, serta pelaku bahkan sebagai obyek pengembangan kepariwisataan perlu mengetahui perannya dalam pengembangan dan pembangunan kepariwisataan. seperti yang diketahui di pantai sulamadaha belum ada kerja sama antar pihak swasta, dalam program rancangan dinas pariwisata di pantai sulamadaha akan melibatkan pihak swasta sebagai stakeholder yang ketiga agar pantai sulamadaha kedepannya lebih baik lagi. (4) Membuat beberapa event yaitu festival tuna dan bevent lainnya yang akan membantu meningkatkan daya tarik di Pantai Sulamadaha.Menghadirkan usaha sebagai pendukung kegiatan wisata seperti kantin, warung, persewaan alat snorkeling, tempat istirahat (tempat duduk) dan perahu kayu.

\section{KESIMPULAN}

Berdasarkan hasil penelitian yang berjudul "Upaya Dinas Pariwisata Dalam Mengatasi Penurunan Tingkat Kunjungan Wisatawan Di sebuah Wisata Pantai Sulamadaha" dapat ditarik kesimpulan sebagai berikut:

1. Penyebab terjadinya penurunan kunjungan wisatawan diketahui ada beberapa faktor yaitu faktor aman, faktor tertib dan faktor ramah-tamah, ketiga faktor ini saling berkaitan dalam bidang pariwisata maka jika ketiga faktor tersebut tidak berjalan maksimal maka akan mempengaruhi jalannya pariwisata yang terdapat di wisata pantai sulamadaha.

2. Upaya Dinas Pariwista Kota Ternate dalam mengatasi penurunan kunjungan wisatawan memiliki peran penting dalam mengambil keputusan serta melakukan strategi mengatasi permasalahan di dtw Pantai Sulamadaha. Seperti pelibatan stakeholder yaitu pihak swasta dalam pengembangan pantai sulamadaha. Mengingat, tidak semua kegiatan pembangunan dapat dikerjakan oleh dinas pariwisata dengan keterbatasan SDM dan finansial. Termasuk peningkatan koordinasi terstruktur secara internal maupun secara eksternal (antar sesama dinas terkait pembangunan pariwisata).

\section{DAFTAR PUSTAKA}

Alendra,E. (2018). Optimalisasi pengelolaan pantai sulamadaha dalam meningkatkan retribusi daerah di sektor kepariwisataan di kota ternate provinsi maluku utara (Doctoral dissertation IPDN)

Amalyah, R., Hamid, D., \& Hakim, L. (2016). Peran Stakeholder Pariwisata Dalam Pengembangan Pulau Samalona Sebagai Destinasi Wisata Bahari. Jurnal Administrasi Bisnis, 37(1), 158-163.

Bungin, B. (2007).Analisis data penelitian kualitatif. PT RajaGrafindo Persada.

Khotimah, K., \& Wilopo, W. (2017). Strategi Pengembangan Destinasi Pariwisata Budaya (Studi Kasus pada Kawasan Situs Trowulan sebagai Pariwisata Budaya Unggulan di Kabupaten Mojokerto). Jurnal Administrasi Bisnis, 42(1), 5665.

Moleong, Lexy. (2002). Metodologi penelitian kualitatif. Bandung: Remaja Rosdakarya.

Mahfud, M. A. Z. (2015). Peran dan Koordinasi Stakeholder dalam Pengembangan Kawasan Minapolitan di Kecamatan Nglegok, Kabupaten Blitar. Jurnal Administrasi Publik, 3(12), 2070-2076.

Nazir, M. (2003). Metode Penelitian Cetakan Kelima. Jakarta: Ghalia Indonesia.

Putri, R. R. A., \& Mahagangga, I. G. A. O. (2013). Upaya Dinas Pariwisata dan Kebudayaan Kota Batam Dalam Kegiatan Wisata Belanja di Kepulauan Riau (Suatu Studi Kualitatif). Jurnal Destinasi Pariwisata, 1(1), 13-24.

Pitana, I., \& Diarta, I. K. G.(2009). Pengantar Ilmu Pariwisata. Yogyakarta. ANDI.

Roku, Y. R., \& Mahagangga, I. G. A. O. (2016). PERAN DAN IMPELEMENTASI STRATEGI PENGEMBANGAN DISBUDPAR KAB. SUMBA TENGAH PROVINSI NTT DALAM PEMBANGUNAN PARIWISATA (SUATU PENDEKATAN KUALITATIF).Jurnal Destinasi Pariwisata ISSN, 2338, 8811.

Suryawan, I. B., \& Mahagangga, I. G. A. O. (2017). Penelitian Lapangan 1. Denpasar: Cakra Media dan Fakultas Pariwisata Universitas Udayana.

Yoeti Oka, A. (1996). Pengantar Ilmu Pariwisata, penerbit PT. Angkasa, Bandung.

Sumber Lain:

Undang-Undang No. 10 tahun 2009 tentang kepariwisataan

Internet:

https://merahputih.com/post/read/pantai-sulamadaha-secuilsurga-di-maluku-utara

https://www.hipwee.com/travel/menikmati-beningnya-pantaisulamadaha-secuil-surga-di-timur-indonesia-indah-banget-men/

https://www.indonesiakaya.com/jelajah-

indonesia/detail/pantai-sulamadaha-oasis-cantik-di-pinggiranpulau-ternate

https://pariwisata.ternatekota.go.id/pantai-sulamadaha.html 